\title{
Development of Green CMP by Slurry Reduction through Controlling Platen Coolant Temperature
}

\author{
Minjong Yuh', Soocheon Jang', Hyoungjae Kim², Hyunseop Lee ${ }^{3}$, and Haedo Jeong',,\# \\ 1 Graduate School of Mechanical Engineering, Pusan National University, 2, Busandaehak-ro 63beon-gil, Geumjeong-gu, Busan, 46241, South Korea \\ 2 Precision Manufacturing and Control Group, Korea Institute of Industrial Technology, 30, Gwahaksandan 1-ro 60beon-gil, Gangseo-gu, Busan, 46742, South Korea \\ 3 Department of Mechanical Engineering, Tongmyong University, 428, Sinseon-ro, Nam-gu, Busan, 48520, South Korea \\ \# Corresponding Author / E-mail: hdjeong@pusan.ac.kr, TEL: +82-51-510-2463, FAX: +82-51-518-8442
}

KEYWORDS: Chemical mechanical polishing (CMP), Copper (Cu), Oscar-Type polisher, Printed circuit board (PCB)

\begin{abstract}
Chemical mechanical polishing (CMP) is currently replacing a conventional chemical etching or mechanical polishing to remove overburdened copper deposit in printed circuit board (PCB) manufacturing process owing to its ability to realize a global planarization. In order to stabilize the CMP as one of the PCB manufacturing processes, the CMP machine has been investigated. This paper introduces a newly developed Oscar-type CMP machine and copper CMP process to polish rectangular PCB with a size up to $510 \mathrm{~mm}$ by $510 \mathrm{~mm}$, especially focused on the effect of platen coolant temperature on removal rate and removal uniformity during copper CMP to reduce the amount of slurry consumed. The CMP experiments are implemented under the coolant temperatures of $10,15,20,25$ and $30^{\circ} \mathrm{C}$, and the slurry flow of $600,800,1000$ and $1200 \mathrm{~mL} / \mathrm{min}$. The experimental results show that the removal rate goes up with an increase in the platen coolant temperature during polishing at a fixed slurry flow rate, and the removal rate goes down at any fixed the platen coolant temperature when the slurry flow rate increases. It means that the reduction of thermochemical reaction rate in the chemical mechanical removal, resulting from cooling down of the copper surface when the.
\end{abstract}

Manuscript received: April 15,2015/Accepted: August 4, 2015 This paper was presented at ISGMA2015

\section{Introduction}

Copper chemical mechanical polishing (CMP) is an essential step in the damascene process of integrated circuit fabrication and other types of electronic components. ${ }^{1,2}$ The CMP process attains a local and global planarization of interlayer dielectrics, tungsten local vias, and multilevel copper interconnects, etc. ${ }^{3,4}$ Semiconductor fabrication still maintains the main application of CMP process; however, its application is now expanding to other related industries. ${ }^{5,6}$ The CMP can also be applied to the fabrication of multilevel circuit boards, packages, flat panel displays, flexible printed circuit boards, organic photovoltaics, etc. Recently, these fabrication processes have required a higher degree of planarity to achieve higher integrity and multistacking, prompting the application of the CMP process instead of conventional etching or mechanical polishing.

A copper CMP process using Oscar-type CMP machine to polish large rectangular flexible substrates was developed to overcome the limitations of conventional CMP systems. However, no previous in-depth studies have discussed the performance of copper CMP process with an Oscar- type CMP machine. In order to establish a novel green CMP process for reducing slurry consumption and understand the material removal mechanism, it is necessary to study the process parameters. In this study, we investigate the effects of the process parameters (down force, platen and carrier rotational speeds, overarm oscillation speed, slurry flow rate, and platen coolant temperature) on the average $\mathrm{MRR}\left(\mathrm{MRR}_{\text {avg }}\right)$ and nonuniformity (NU) in a copper CMP process using an Oscar-type CMP machine to understand the material removal mechanism.

\section{Experiments}

\subsection{Oscar-Type CMP Machine}

Experiments were conducted on an Oscar-type CMP machine manufactured by GnP Technology Inc. The CMP machine can accommodate up to $915 \mathrm{~mm}$ diameter substrate and the platen can hold up to $1300 \mathrm{~mm}$ diameter polishing pad, and ex-situ brush conditioning can be done on the polisher. The substrate mounted to the polishing head under the overarm, the overarm pivot oscillates laterally the 
polishing head on the spinning platen with an attached polishing pad. The slurry delivered to the polishing pad through holes in the center of the platen. Fig. 1 is a schematic diagram of Oscar-type CMP machine, and Fig. 2 is a photograph of the actual system.

\subsection{Consumables and Process Conditions}

$\mathrm{Cu}$ CMP slurry (MS5000, Nitta Haas Inc.) with $3.2 \mathrm{wt} \%$ hydrogen peroxide $\left(\mathrm{H}_{2} \mathrm{O}_{2}\right)$ was prepared for polishing of $510 \times 510 \times 0.56 \mathrm{~mm}$ sized copper-clad laminate (CCL) which has a $35 \mu \mathrm{m} \mathrm{Cu}$ film on polymer substrate. Polishing pad was a polymer impregnated felt
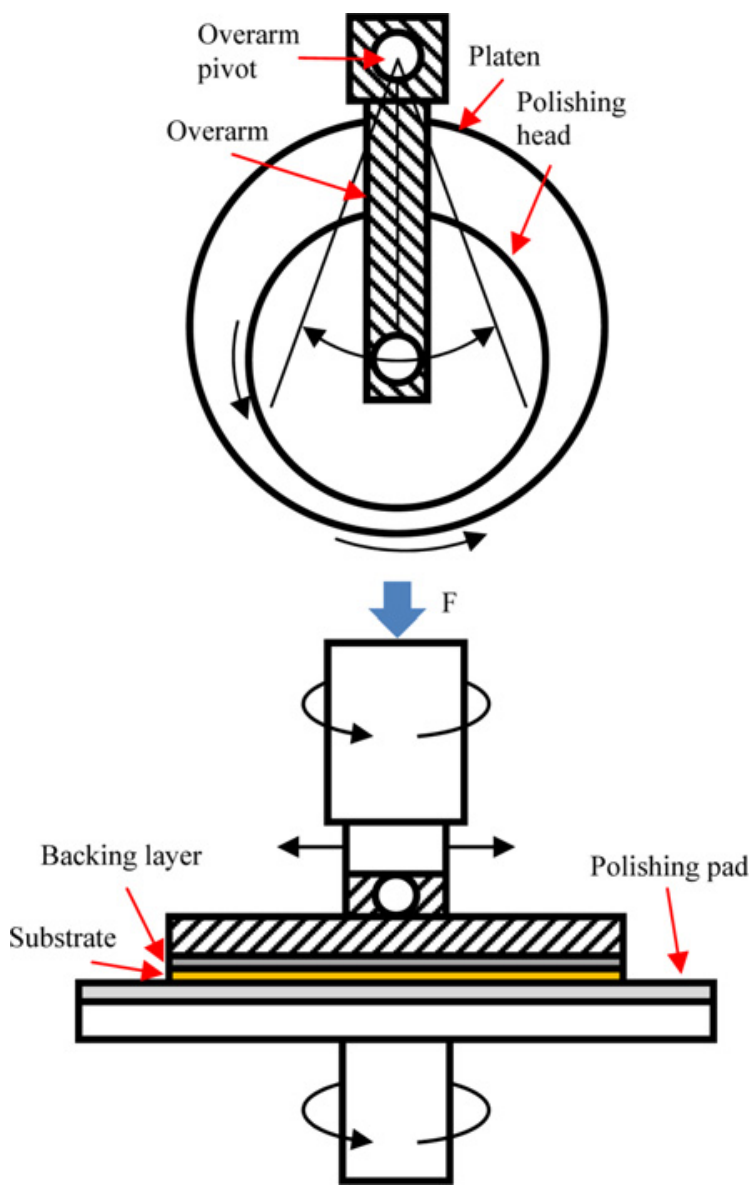

Fig. 1 Schematic diagram of Oscar-Type CMP machine

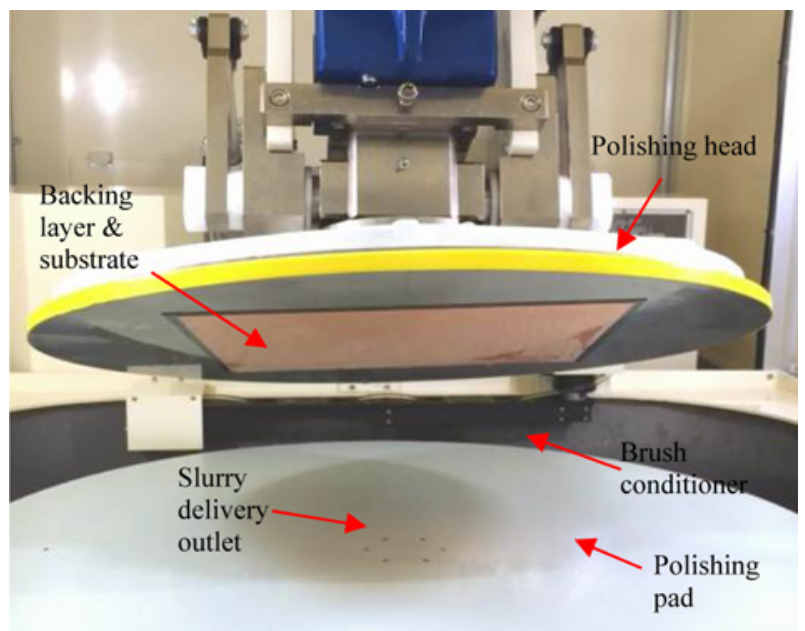

Fig. 2 Photograph of actual Oscar-Type CMP machine
(SUBA $600 \mathrm{XY}$ groove, Nitta Haas Inc.), and was punched with three holes in the center for delivering slurry.

The process parameters for the Oscar-type CMP machine are down force, rotation speeds of the platen and head, overarm oscillation speed, slurry flow rate, and platen coolant temperature. Experimental conditions are listed in Table 1. The thickness of the $\mathrm{Cu}$ film was measured with a four-point probe (SR-scope, Fischer Technology, Inc.). The edge exclusion in the $\mathrm{x}$ and $\mathrm{y}$ directions were $30 \mathrm{~mm}$, respectively. Total of 41 points were measured along with $\mathrm{x}$ and $\mathrm{y}$ directions. The $\mathrm{NU}$ of the MRRs was calculated as

$$
N U(\%)=\frac{\sigma}{M R R_{\text {avg }}} \times 100
$$

Where $\sigma$ is the standard deviation of the material removal rates, and $M R R_{\text {avg }}$ is the mean value of the material removal rates.

\section{Results and Discussion}

\subsection{Down Force and Rotational Speeds of Platen and Head}

Fig. 3 shows the effects of down force and rotational speeds of platen and head on the $\mathrm{MRR}_{\text {avg }}$ and NU of the MRRs. The down force of the carrier was varied from 3.82 to $7.65 \mathrm{kN}$, platen and head rotational speeds were changed from 30 to $75 \mathrm{rpm}$. The highest $\mathrm{MRR}_{\text {avg }}$ was $4.1 \mu \mathrm{m} / \mathrm{min}$ (7.65 $\mathrm{kN}$ down force, $75 \mathrm{rpm}$ platen and head speeds), the lowest $\mathrm{MRR}_{\text {avg }}$ was $1.2 \mu \mathrm{m} / \mathrm{min}$ (3.82 kn down force, $30 \mathrm{rpm}$ platen and head speeds). The NU varied from $14.4 \%$ (5.1 kN down force, 60 rpm platen and head speeds) to $34.2 \%$ (3.82 kN down force, $30 \mathrm{rpm}$ platen and carrier speeds) according to process conditions.

From Fig. 3 it can be seen that the $M_{R R}$ avg increases with an increase in the down force and rotational speeds. The NU initially reduces with an increase in rotational speeds up to $60 \mathrm{rpm}$ and then increases with a further increase in rotational speed. Thus it appears likely that the down force should be increased and rotational speeds should be about $60 \mathrm{rpm}$ to obtain high $\mathrm{MRR}_{\text {avg }}$ and low NU.

According to Preston's equation, ${ }^{7}$ the product of the applied pressure and the relative velocity between the substrate and the polishing pad makes a significant contribution to MRR in a CMP process. Fig. 4 shows that the $\mathrm{MRR}_{\text {avg }}$ of Oscar-type CMP process conforms to Preston's equation. The $\mathrm{MRR}_{\mathrm{avg}}$ increases linearly with the product of the pressure and the relative velocity between the sliding substrate and the rotating polishing pad.

\subsection{Overarm Oscillation Speed}

Fig. 5 illustrates the kinematic parameters of the Oscar-type CMP

Table 1 Experimental conditions

\begin{tabular}{cc}
\hline Parameters & Conditions \\
\hline Substrate & CCL, $510 \mathrm{~mm} \times 510 \mathrm{~mm} \times 0.56 \mathrm{~mm}$ \\
Pad & SUBA600 (Nitta Haas) \\
Slurry & MS5000 (Nitta Haas) \\
Down force & $3.28-8.04 \mathrm{kN}$ \\
Platen and head rotational speeds & $30-75 \mathrm{rpm}$ \\
Overarm oscillation speed & $0-8 \mathrm{rpm}$ \\
Slurry flow rate & $600-1200 \mathrm{~mL} / \mathrm{min}$ \\
Platen coolant temperature & $10-30^{\circ} \mathrm{C}$
\end{tabular}


machine. $O$ and $O^{\prime}$ represent the origin of the coordinate system located on the platen (or pad) and the polishing head (or substrate), respectively. $\omega_{p}, \omega_{c}$ and $\omega_{o}$ represent the angular velocities of platen, head and overarm, respectively. $\vec{P}(t), \vec{D}(t)$ and $\vec{r}$ are the position vectors from $O$ to $A$, from $O$ to $O$, and from $O$ ' to $A$, respectively. The position vector $\vec{P}(t)$ as a function of process time (t) can be written as

$$
\vec{P}(t)=\vec{D}(t)+\vec{r}(t)=P_{x} \cdot \hat{i}+P_{y}(t) \cdot \hat{j}
$$

Where $\hat{i}$ and $\hat{j}$ are the unit vectors of the $\mathrm{x}$ and $\mathrm{y}$ directions in the coordination system. The relative velocity at the arbitrary position $A$

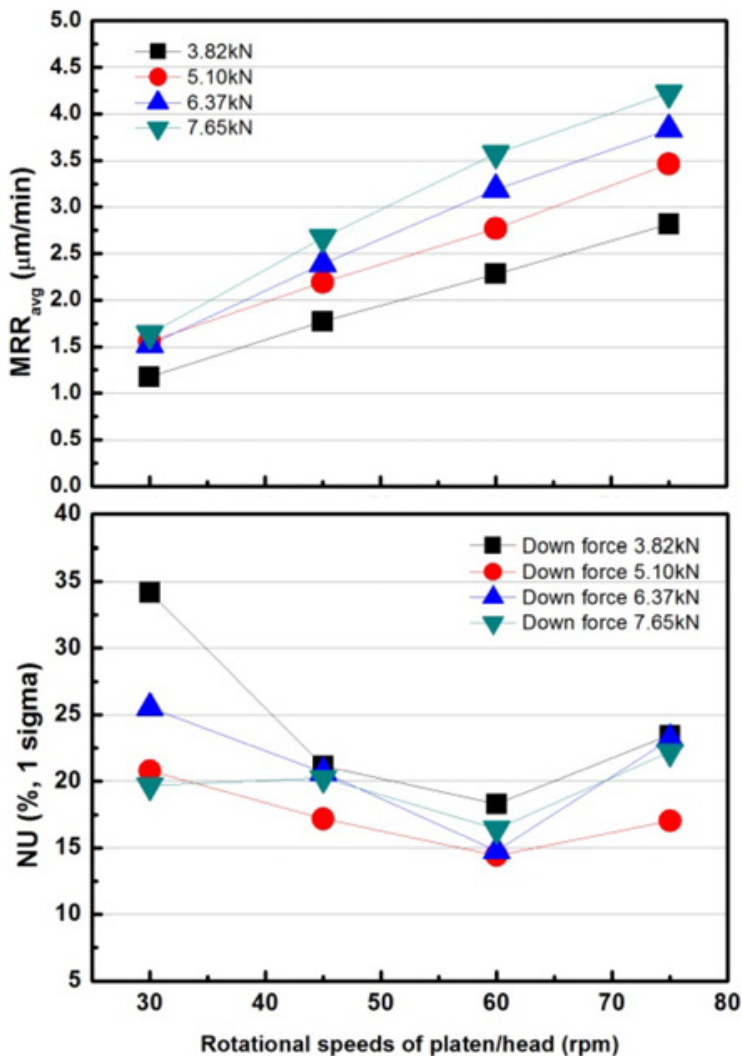

Fig. 3 Variation in $\mathrm{MRR}_{\text {avg }}$ and NU with down force and rotational speeds of platen and head

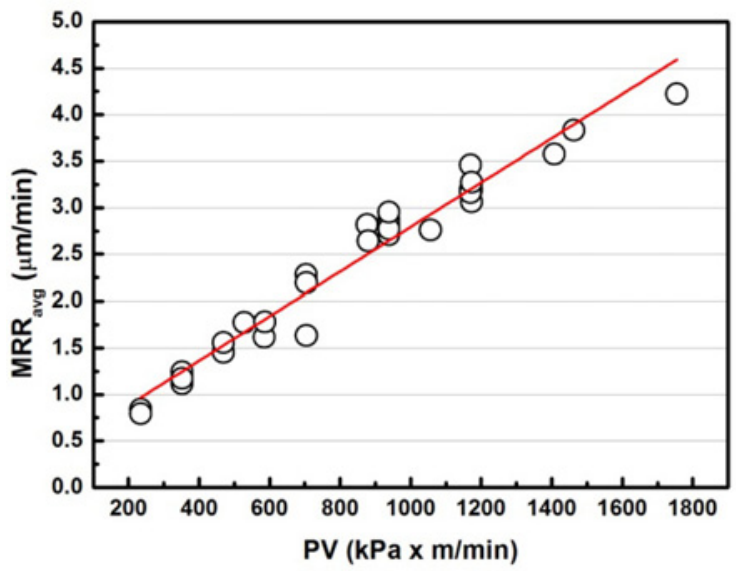

Fig. $4 \mathrm{MRR}_{\text {avg }}$ obtained experimentally as a function of the product of the pressure and the relative velocity is the derivative of $\vec{V}(t)$ with respect to process time $\mathrm{t}$ as shown below.

$$
\vec{V}(t)=\frac{d}{d t} \vec{P}(t)=\frac{d P_{x}(t)}{d t} \cdot \hat{i}+\frac{d P_{y}(t)}{d t} \cdot \hat{j}
$$

The magnitude of the relative velocity at an arbitrary position $(\mathrm{x}, \mathrm{y})$ on the substrate can be calculated as

$$
V(x, y, t)=\sqrt{\frac{d P_{x}(t)^{2}}{d t}+\frac{d P_{y}(t)^{2}}{d t}}
$$

The magnitude of relative velocity affects the MRR, but its direction does not Ref. 8. Among the kinematic variables, $\omega_{p}$ is the dominant parameter in the relative velocity magnitude. $\omega_{o}$ also affects the relative velocity magnitude but less than $\omega_{p} . \omega_{c}$ mainly affects the resulting cycle frequency of the relative velocity magnitude.

Fig. 6 shows the effect of the overarm oscillation speed on the average relative velocity and the $M_{R} R_{\text {avg }}$. The lowest $M R R_{\text {avg }}$ is $2.6 \mu \mathrm{m} / \mathrm{min}$ at the overarm oscillation speed of $0 \mathrm{rpm}$. The $\mathrm{MRR}_{\text {avg }}$ increases with an increase in the overarm oscillation speed. There are no significant changes in $\mathrm{MRR}_{\text {avg }}$ when the overarm oscillation speeds excesses $2 \mathrm{rpm}$. Since the overarm oscillation speed is quite small compared with platen and head rotational speeds, its effect on the average relative velocity is not important.

\subsection{Slurry Flow Rate}

The slurry flow rate affects the material removal characteristics by

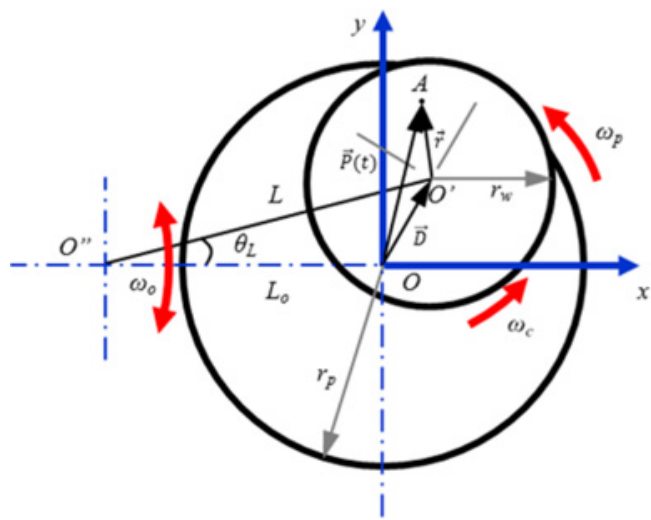

Fig. 5 Kinematic diagram of Oscar-Type CMP machine

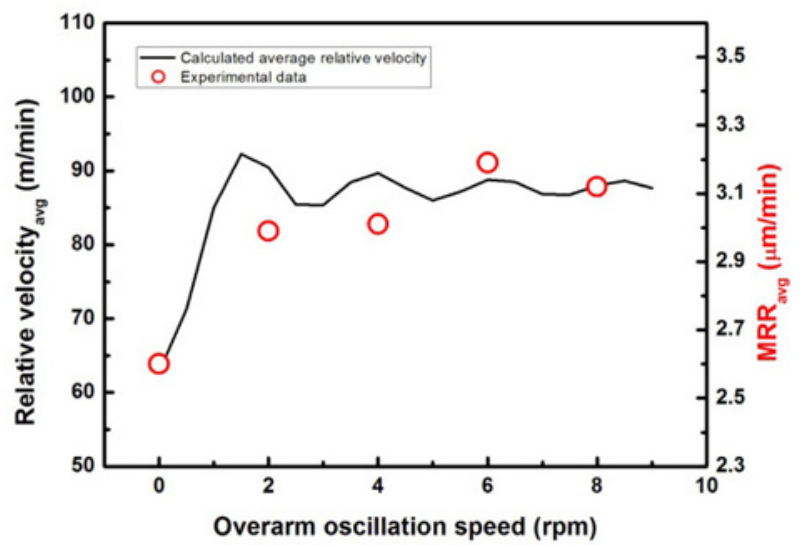

Fig. 6 Calculated average relative velocity and experimental $M R R_{\text {avg }}$ as a function of overarm oscillation speed $\left(\omega_{p}=\omega_{c}=60 \mathrm{rpm}\right.$, $L=868 \mathrm{~mm}, L_{o}=768$, down force: $6.37 \mathrm{kN}$ ) 
changing the interaction between abrasives and chemicals. Fig. 7 shows that the effects of the slurry flow rate on $\mathrm{MRR}_{\text {avg }}$ and $\mathrm{NU}$. The down force is $8.04 \mathrm{kN}$, platen and head rotational speeds are $50 \mathrm{rpm}$ and the platen coolant temperature is $20^{\circ} \mathrm{C}$. It can be seen that $\mathrm{MRR}_{\text {avg }}$ increases when the slurry flow rate increases from 600 to $1000 \mathrm{~mL} /$ min, and then decreases by further increase in the slurry flow rate. Subrahamanya et al. ${ }^{9}$ showed that coefficient of friction decreased and removal rate increased with an increase in slurry flow rate. Li et al. ${ }^{10}$ showed that the decrease in material removal rate with increasing slurry flow rate attributed the change to the cooling of the wafer by the slurry in copper polishing. The reasons for the change in $M_{R R}$ avg with increase in slurry flow rate are due to the change in coefficient of friction and substrate surface cooling effect. As the higher slurry flow rate decreases the temperature at the interface between the substrate and the polishing pad, $\mathrm{MRR}_{\text {avg }}$ decreases at a slurry flow rate of $1200 \mathrm{~mL} / \mathrm{min}$.

Increasing the slurry flow rate from 600 to $1200 \mathrm{~mL} / \mathrm{min}$ reduces NU. Since the slurry supplied to the interface between substrate and pad through holes in the center of the polishing pad in Oscar-type CMP machine, the higher slurry flow rate can transport fresh slurry from center to the edge of the polishing pad. From Fig. 8 it can be seen that the center area of substrate was polished more rapidly than the edge area of substrate at the lower slurry flow rate. The MRR difference between center and edge area was reduced at the higher slurry flow
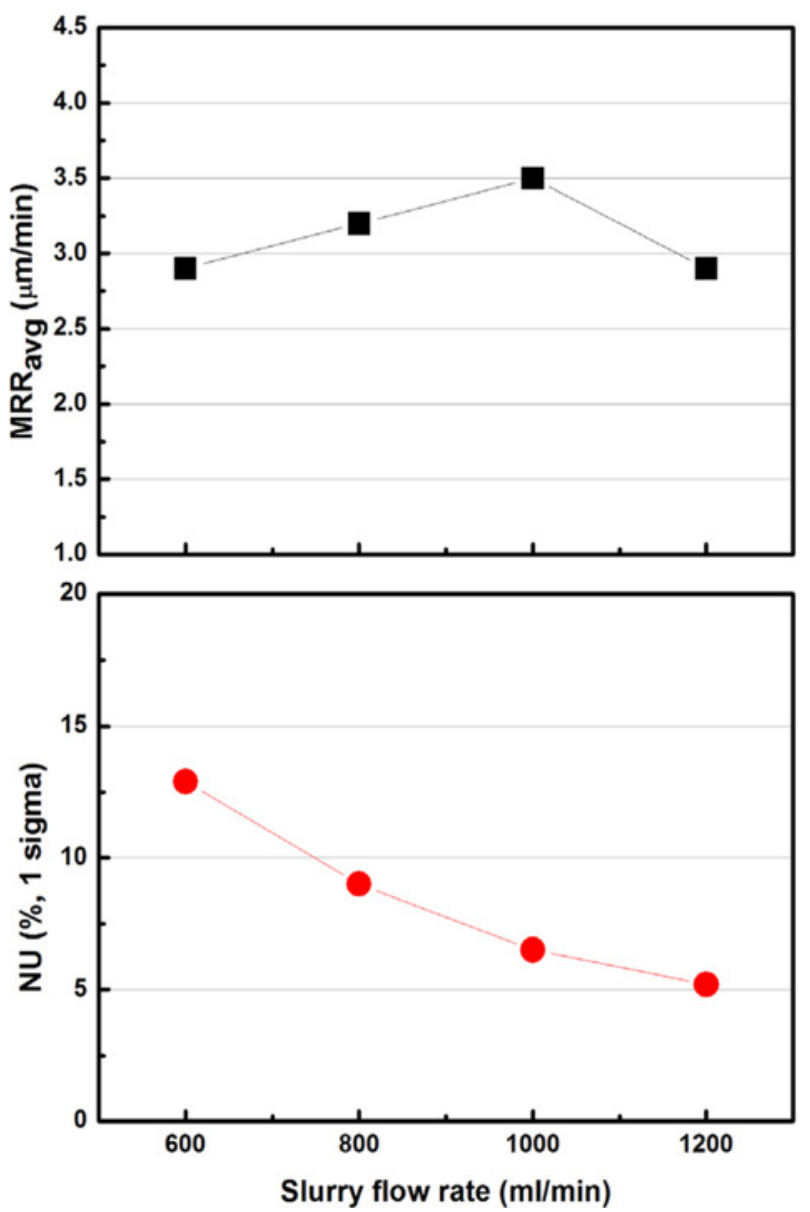

Fig. $7 \mathrm{MRR}_{\text {avg }}$ and $\mathrm{NU}$ data at different slurry flow rate (down force: $8.04 \mathrm{kN}$, platen and head speed: $50 \mathrm{rpm}$, platen coolant temperature: $\left.20^{\circ} \mathrm{C}\right)$ rate. It implies that a sufficiently large slurry flow rate results in a low NU.

\subsection{Platen Coolant Temperature}

Pad temperature influences the material removal rate by changing the pad properties and chemical reaction rate. Kakireddy et al. ${ }^{11}$ showed that the coefficient of friction and removal rate increased with an increase in temperature during polishing. This change in the coefficient of friction is due to the increased contact area of the padsubstrate surface with an increase in temperature, resulting in a higher shear force at the interface, which can be supported by the change in COF with the change in temperature. Kim et al. ${ }^{12}$ showed that the contact area increases with temperature caused by the decrease of asperity hardness due to the temperature elevation. Lee et al. ${ }^{13}$ showed that the rise of the pad temperature increases the temperature of the slurry flow in the pad-substrate interface.

In our experiment, the platen coolant temperature is adjusted from 10 to $30^{\circ} \mathrm{C}$ to verify the effect of elevating pad temperature in the process. The platen coolant flows through circular shaped channels as shown in Fig. 9. The down force is $8.04 \mathrm{kN}$, rotational speeds of the platen and head are $50 \mathrm{rpm}$ and the slurry flow rates are changed from 600 to $1200 \mathrm{~mL} / \mathrm{min}$. From Fig. 10, it can be seen that the $\mathrm{MRR}_{\text {avg }}$ are increased with an increase in the platen coolant temperature. The observed increase in $\mathrm{MRR}_{\text {avg }}$ might be due to increase in contact area between the substrate and the pad. This increase in contact area results in reduction of the overall load experienced by the pad. It is the nature of polymer materials that the COF increases with reduction in applied load when in contact with a hard inelastic material. From Fig. 10, it can

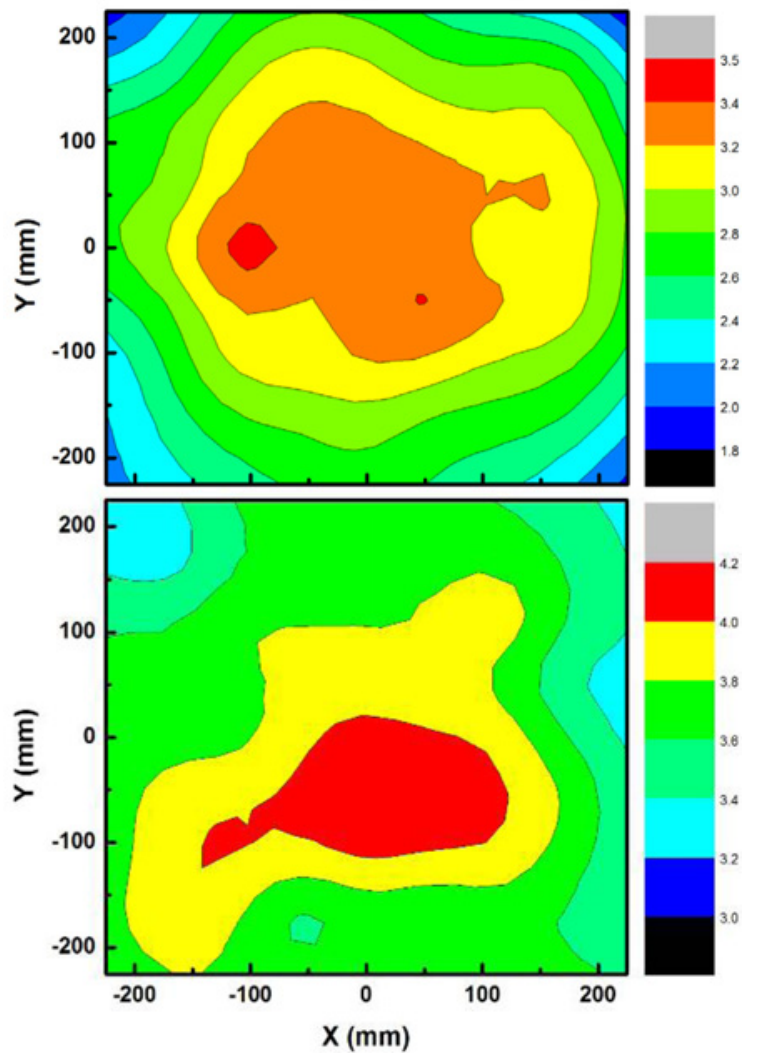

Fig. 8 Examples of MRR contour map of slurry flow rate at (a) 600 , (b) $1200 \mathrm{~mL} / \mathrm{min}$ 
be seen that the NU of MRRs reduces with an increase in the platen coolant temperature except at a slurry flow of $600 \mathrm{~mL} / \mathrm{min}$. The observed trend of the NU can be attributed to the changes in the slurry viscosity. Viscosity is a very temperature dependent parameter, whereby small variations in temperature can produce large variations in viscosity. As the higher platen coolant temperature decreases the slurry viscosity, fresh slurry can transport to edge of the pad. The higher platen coolant temperature leads to a superfluous chemically reacted area on the substrate without the cooling effect. These results indicate that high MRR and low NU are attained by increasing the platen coolant temperature rather than increasing the slurry flow rate.

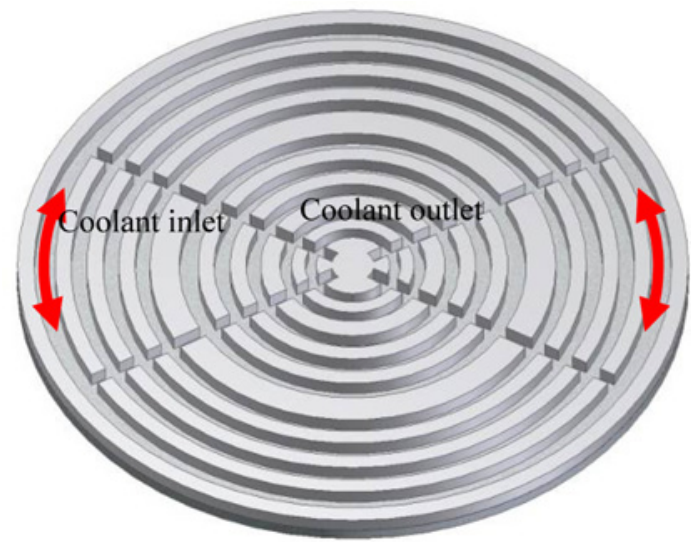

Fig. 9 Circular shaped platen coolant channels

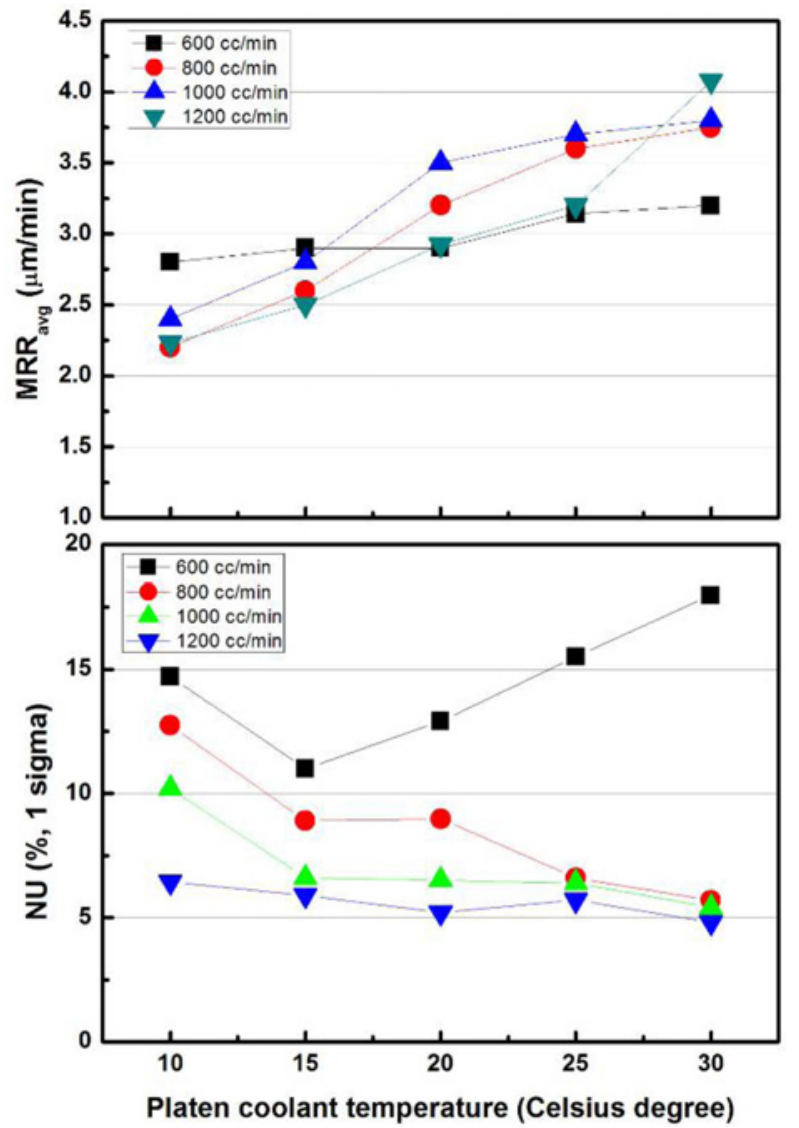

Fig. $10 \mathrm{MRR}_{\text {avg }}$ and $\mathrm{NU}$ data at different platen coolant temperature (down force: $8.04 \mathrm{kN}$, platen and head speed: $50 \mathrm{rpm}$ )

\section{Conclusions}

This paper has described the process parameters for the newly developed Oscar-type CMP machine and copper CMP process for the flexible CCL substrate with a size up to $510 \mathrm{~mm}$ by $510 \mathrm{~mm}$. From the viewpoint of average MRR, Oscar-type CMP machine process conforms to the traditional Preston's equation. The overarm oscillation speed is quite small compared with platen speed and head rotational speed, its effect on the average relative velocity is not significant except at $0 \mathrm{rpm}$. The $\mathrm{MRR}_{\text {avg }}$ increased and the NU improved with an increase in slurry flow rate up to $1000 \mathrm{~mL} / \mathrm{min}$ and then decreased with a further increase in slurry flow rate. This could be attributed to the decrease in the temperature at the interface between the substrate and the polishing pad. Finally, the platen coolant temperature directly influences the $\mathrm{MRR}_{\text {avg }}$ and the NU. The MRR ${ }_{\text {avg }}$ increased with an increase in platen coolant temperature without cooling effect at the interface of the substrate and pad. The NU also improved at higher platen coolant temperature. Thus, high MRR and low NU were attained by increasing platen coolant temperature in spite of the reduction of slurry consumption. For the experiment described in this paper, we used a newly developed Oscar-type CMP machine and copper CMP process for PCB rectangular panels. This preliminary study may be helpful for expanding the range of fields to which Oscar-type CMP machine and copper CMP process is applied.

\section{ACKNOWLEDGEMENT}

This research was supported by G\&P Technology Inc., Korea and Nitta Haas Inc., Japan.

\section{REFERENCES}

1. Pandija, S., Roy, D., and Babu, S., "Achievement of High Planarization Efficiency in CMP of Copper at a Reduced Down Pressure," Microelectronic Engineering, Vol. 86, No. 3, pp. 367-373, 2009.

2. Lee, H., Wang, H., Park, J., and Jeong, H., "Experimental Investigation of Process Parameters for Roll-Type Linear Chemical Mechanical Polishing (Roll-CMP) System,” Precision Engineering, Vol. 38, No. 4, pp. 928-934, 2014.

3. Lee, H., Joo, S., Kim, H., and Jeong, H., "Chemical Mechanical Planarization Method For Thick Copper Films of Micro-ElectroMechanical Systems and Integrated Circuits," Japanese Journal of Applied Physics, Vol. 47, No. 7R, Paper No. 5708, 2008.

4. Lee, H. and Jeong, H., "Chemical and Mechanical Balance in Polishing of Electronic Materials for Defect-Free Surfaces," CIRP Annals-Manufacturing Technology, Vol. 58, No. 1, pp. 485-490, 2009.

5. Jeong, M., Jo, S., Lee, H., Lee, A., Kang, C., et al., "Chemical Mechanical Planarization of Copper Bumps on Printed Circuit Board,” Int. J. Precis. Eng. Manuf., Vol. 12, No. 1, pp. 149-152, 2011. 
6. Vaes, N. and Jan, H., "CMP Processing to Enable 3D Stacked IC Integration," Proc. of the International Conference on Planarization/ CMP Technology, pp. 105-112, 2009.

7. Preston, F. W., "The Theory and Design of Plate Glass Polishing Machine," Journal of the Society of Glass Technology, Vol. 11, pp. 214-256, 1927.

8. Hocheng, H., Tsai, H., and Tsai, M., "Effects of Kinematic Variables on Nonuniformity in Chemical Mechanical Planarization," International Journal of Machine Tools and Manufacture, Vol. 40, No. 11, pp. 1651-1669, 2000.

9. Mudhivarthi, S., Gitis, N., Kuiry, S., Vinogradov, M., and Kumar, A., "Effects of Slurry Flow Rate and Pad Conditioning Temperature on Dishing, Erosion, and Metal Loss during Copper CMP," Journal of the Electrochemical Society, Vol. 153, No. 5, pp. G372-G378, 2006.

10. Li, Z., Borucki, L., Koshiyama, I., and Philipossian, A., "Effect of Slurry Flow Rate on Tribological, Thermal, and Removal Rate Attributes of Copper CMP," Journal of the Electrochemical Society, Vol. 151, No. 7, pp. G482-G487, 2004.

11. Kakireddy, V. R., Mudhivarthi, S., and Kumar, A., "Effect of Temperature on Copper Damascene Chemical Mechanical Polishing Process," Journal of Vacuum Science \& Technology B, Vol. 26, No. 1, pp. 141-150, 2008.

12. Kim, H., Kim, H., Jeong, H., Lee, E., and Shin, Y., "Friction and Thermal Phenomena in Chemical Mechanical Polishing," Journal of Materials Processing Technology, Vol. 130, pp. 334-338, 2002.

13. Lee, H., Guo, Y., and Jeong, H., "Temperature Distribution in Polishing Pad during CMP Process: Effect of Retaining Ring," Int. J. Precis. Eng. Manuf., Vol. 13, No. 1, pp. 25-31, 2012. 